\title{
Perforated Active Carbon and Pre-Lithiated Graphite Electrodes for High Performance Hybrid Lithium-ion Capacitors
}

\author{
Yifei Ren, Jing Li*, Jianqiang Guo
}

School of Materials Science and Engineering, Southwest University of Science and Technology, Mianyang, Sichuan 621010, China

*E-mail: $879763801 @$ qq.com

doi: $10.20964 / 2020.03 .03$

Received: 31 October 2019 / Accepted: 26 November 2019 / Published: 10 February 2020

Lithium-ion capacitors are kinds of advanced energy storage systems, which possess performance of lithium-ion battery and electrical double layer capacitor. In this work, we have developed a new method to realize the pre-lithiation of graphite anode and fabricated lithium-ion hybrid capacitors with two cathodes including capacitor cathode (activated carbon) and battery cathode $\left(\mathrm{LiCO}_{2}\right)$. The electrochemical performances indicate that the open-circuit voltage of the hybrid lithium-ion capacitor is nearly $0 \mathrm{~V}$ before the pre-lithiation. Finally, the voltage that rising with the process of pre-lithiation is up to $3.8 \mathrm{~V}$. Meanwhile, the voltage of graphite electrode decreases from $3 \mathrm{~V}$ to $0 \mathrm{~V} \mathrm{vs} \mathrm{Li}^{-} / \mathrm{Li}^{+}$. The electrochemical results indicate that the capacitance of the hybrid lithium-ion capacitor decreased less than $1 \%$ after 300 cycles.

Keywords: Lithium-ion hybrid capacitor; Pre-lithiation; $\mathrm{LiCO}_{2}$; Activated carbon; Graphite

\section{$\underline{\text { FULL TEXT }}$}

(C) 2020 The Authors. Published by ESG (www.electrochemsci.org). This article is an open access article distributed under the terms and conditions of the Creative Commons Attribution license (http://creativecommons.org/licenses/by/4.0/). 